\title{
Implications of soil and canopy temperature uncertainty in the estimation of surface energy fluxes using TSEB2T and high-resolution imagery in commercial vineyards
}

Nassar, Ayman, Torres-Rua, Alfonso, Kustas, William, Nieto, Hector, McKee, Mac, et al.

Ayman Nassar, Alfonso Torres-Rua, William Kustas, Hector Nieto, Mac McKee, Lawrence Hipps, Joseph Alfieri, John Prueger, Maria Mar Alsina, Lynn McKee, Calvin Coopmans, Luis Sanchez, Nick Dokoozlian, "Implications of soil and canopy temperature uncertainty in the estimation of surface energy fluxes using TSEB2T and high-resolution imagery in commercial vineyards," Proc. SPIE 11414, Autonomous Air and Ground Sensing Systems for Agricultural Optimization and Phenotyping V, 114140F (26 May 2020); doi: $10.1117 / 12.2558715$ 


\title{
Implications of Soil and Canopy Temperature Uncertainty in the Estimation of Surface Energy Fluxes Using TSEB2T and High- resolution Imagery in Commercial Vineyards
}

\author{
Ayman Nassar ${ }^{a, *}$, Alfonso Torres-Rua a, William Kustas ${ }^{\text {b }}$, Hector Nieto ${ }^{\text {c, Mac McKee }}{ }^{\text {a }}$, \\ Lawrence Hipps ${ }^{\text {d, Joseph Alfieri }}{ }^{\text {b }}$, John Prueger ${ }^{\text {e, Maria Mar Alsina }}{ }^{\text {f }}$, Lynn McKee ${ }^{\text {b, }}$ \\ Calvin Coopmans ${ }^{g}$, Luis Sanchez ${ }^{f}$ and Nick Dokoozlian ${ }^{f}$ \\ ${ }^{a}$ Department of Civil and Environmental Engineering, Utah State University, Logan, UT \\ 84322, USA; Alfonso.Torres@usu.edu (A.F.T.-R.); mac.mckee@usu.edu (M.M.) \\ b U. S. Department of Agriculture, Agricultural Research Service, Hydrology and Remote \\ Sensing Laboratory, Beltsville, MD 20705, USA; bill.kustas@usda.gov (W.P.K.); \\ Joe.Alfieri@ars.usda.gov (J.A); lynn.mckee@ars.usda.gov (L.M.) \\ c Complutum Tecnologías de la Información Geográfica (COMPLUTIG), Madrid, Spain; \\ hector.nieto@complutig.com (H.N.) \\ d Plants, Soils and Climate Department, Utah State University, Logan, UT 84322, USA; \\ Lawrence.Hipps@usu.edu (L.H.) \\ e U. S. Department of Agriculture, Agricultural Research Service, National Laboratory \\ for Agriculture and the Environment, Ames, IA 50011, USA; john.prueger@usda.gov \\ (J.H.P.) f E \& J Gallo Winery Viticulture Research, Modesto, CA 95354, USA; \\ MariadelMar.Alsina@ejgallo.com (M.M.A.); Luis.Sanchez@ejgallo.com (L.S.); \\ Nick.Dokoozlian@ejgallo.com (N.D.) \\ g Department of Electrical Engineering, Utah State University, Logan, UT 84322, USA; \\ cal.coopmans@usu.edu (C.C.) \\ * Correspondence: aymnassar@aggiemail.usu.edu
}

\begin{abstract}
Estimation of surface energy fluxes using thermal remote sensing-based energy balance models (e.g., TSEB2T) involves the use of local micrometeorological input data of air temperature, wind speed, and incoming solar radiation, as well as vegetation cover and accurate land surface temperature (LST). The physically based Two-source Energy Balance with a Dual Temperature (TSEB2T) model separates soil and canopy temperature $\left(T_{s}\right.$ and $\left.T_{c}\right)$ to estimate surface energy fluxes including $R_{n}, H, L E$, and $G$. The estimation of $T_{s}$ and $T_{c}$ components for the TSEB2T model relies on the linear relationship between the composite land surface temperature and a vegetation index, namely NDVI. While canopy and soil temperatures are controlling variables in the TSEB2T model, they are influenced by the NDVI threshold values, where the uncertainties in their estimation can degrade the accuracy of surface energy flux estimation. Therefore, in this research effort, the effect of uncertainty in $T_{s}$ and $T_{c}$ estimation on surface energy fluxes will be examined by applying a Monte Carlo simulation on NDVI thresholds used to define canopy and soil temperatures. The spatial information used is available from multispectral imagery acquired by the AggieAir sUAS Program at Utah State University over vineyards near Lodi, California as part of the ARS-USDA Agricultural Research Service's Grape Remote Sensing Atmospheric Profile and Evapotranspiration eXperiment (GRAPEX) project. The results indicate that LE is slightly sensitive to the uncertainty of $\mathrm{NDVI}_{\mathrm{s}}$ and $\mathrm{NDVI}_{\mathrm{c}}$. The observed relative error of LE corresponding to $\mathrm{NDVI}_{\mathrm{s}}$ uncertainty was between $-1 \%$ and $2 \%$, while for $\mathrm{NDVI}_{\mathrm{c}}$ uncertainty, the relative error was between $-2.2 \%$ and $1.2 \%$. However, when the combined $\mathrm{NDVI}_{\mathrm{s}}$ and $\mathrm{NDVI}_{\mathrm{c}}$ uncertainties were used simultaneously, the domain of the observed relative error corresponding to the absolute values of $|\Delta \mathrm{LE}|$ was between $0 \%$ and $4 \%$.
\end{abstract}

Keywords: TSEB2T, surface energy fluxes, land surface temperature (LST), soil and canopy temperature $\left(T_{s}, T_{c}\right)$, sensitivity analysis, LST uncertainty, Monte Carlo simulation 


\section{INTRODUCTION}

Evapotranspiration (ET) is a key component for hydrology and agricultural water management. Accurate estimation of ET is essential for a better understanding of the interactions between water and energy cycles ${ }^{1}$, climate change ${ }^{2}$, droughts ${ }^{3}$, and plant growth ${ }^{4}$. Most water in the hydrological cycle is consumed through ET, which returns approximately 70 percent of precipitation on land to the atmosphere ${ }^{5}$. For irrigated agriculture, ET is considered a key indicator for quantifying crop water demand, irrigation scheduling, and vegetation stress ${ }^{6}$. Many approaches have been developed for measuring actual ET, including eddy covariance flux towers ${ }^{7}$, lysimeters ${ }^{8}$, and scintillometers ${ }^{9}$; however, use of these methods is limited to point measurement with an assumption of surface homogeneity, which is unlikely to be the case in reality ${ }^{10,11}$. On the other hand, the use of indirect measurements, such as Bowen ratio stations and evaporative pans, is limited to small areas and entails considerable labor ${ }^{12}$.

Nowadays, the advent of remote sensing technology using a variety of platforms can provide an unprecedented opportunity to produce spatiotemporal ET information at different spatial scales spanning from sub-meters to kilometers. However, ET is not sensed directly but instead requires a combination of ground observations and remotely sensed data, from satellites, aircraft, or sUAS ${ }^{13}$, and is grounded in the theory behind the surface energy balance model. The applications and validation of these models involve the micrometeorological inputs of air temperature, wind speed, water vapor pressure and incoming solar radiation, as well as vegetation cover and accurate land surface temperature (LST). For energy balance models such as TSEB, LST is considered a critical component that is strongly coupled to ET estimates. From an operational applications perspective, local information could present some challenges in those models, particularly the LST, which is not routinely available. Moreover, the spatial LST information obtained from remote sensors might have some degree of uncertainty due to atmospheric effects, surface emissivity, calibration issues, and radiometer viewing angle ${ }^{6}$. Prata et al. $1995{ }^{14}$ pointed out that LST changes rapidly due to high spatial heterogeneity in the land surface characteristics such as soil, vegetation, and topography ${ }^{15}$. Therefore, surface energy fluxes, and in particular LE, could be highly influenced as LST and micro-meteorological conditions together could render the approaches that rely on surface-air differences.

Estimating ET with the uncertainty in LST over heterogeneous areas remains a challenging task as LST is commonly known to exhibit high temporal-spatial variation. Kustas and Norman $1996{ }^{16}$ indicated that LST must be retrieved at an accuracy of $1 \mathrm{~K}$ or less to better understand the earth system and achieve ET accuracy less than $10 \%$. However, aside from the spatial variability of emissivity, atmospheric effects make it difficult to perform the models with that accuracy ${ }^{17}$. While several models have been developed to estimate ET based on the energy balance approach, it can be difficult to apply these models without accurate LST retrieval. In surface energy balance models such as TSEB, separation between canopy and soil temperatures $\left(\mathrm{T}_{\mathrm{c}}\right.$ and $\mathrm{T}_{\mathrm{s}}$, respectively) is needed for quantifying the ET components: evaporation (E) and transpiration (T).

The impact of LST uncertainty on ET retrieval using remote sensing models has rarely been studied. This is true particularly for the Two-source Energy Balance with a Dual Temperature (TSEB2T) model, which requires $T_{c}$ and $T_{s}$ components, derived from LST, as key inputs. As described in section (2.2), threshold values of NDVI $\mathrm{I}_{\mathrm{s}}$ and NDVI $\mathrm{N}_{\mathrm{c}}$ are the main variables used to determine $T_{c}$ and $T_{s}$ in the relationship of LST-NDVI ${ }^{18}$. Depending on the LST-NDVI relationship, small changes in these variables could result in changes to the $T_{c}$ and $T_{s}$ values. This implies that an accurate estimation for $\mathrm{NDVI}_{\mathrm{s}}$ and $\mathrm{NDVI}_{\mathrm{c}}$ is needed to calculate $\mathrm{T}_{\mathrm{c}}$ and $\mathrm{T}_{\mathrm{s}}$ with less uncertainty. In this research effort, the sensitivity analysis is performed to evaluate the response of the TSEB2T model to changes in the temperature components involving canopy and soil temperature $\left(\mathrm{T}_{\mathrm{c}}\right.$ and $\mathrm{T}_{\mathrm{s}}$, respectively). Of particular interest is how the sensitivity of these parameters $\left(T_{c}\right.$ and $T_{s}$ ) changes with changes in the threshold values of NDVI (NDVI $I_{c}$ and $\left.N_{D V I}\right)$. The model is applied over vineyards: a complex environment domain in which $\mathrm{T}_{\mathrm{c}}$ and $\mathrm{T}_{\mathrm{s}}$ vary considerably. Other parameters, including meteorological conditions and crop and soil characteristics, remain the same with no change.

\subsection{Study area}

\section{METHODOLOGY}

As illustrated in Figure (1), the experimental work has been conducted over a wine grape vineyard located near Lodi, California $\left(38.29^{0} \mathrm{~N}, 121.12^{0} \mathrm{~W}\right){ }^{19,20}$ with an area of approximately 62 ha. The study area involves one vineyard blocks (north) that is part of the Sierra Loma vineyard ranch, owned by McMannis Winery ${ }^{21}$ and managed by Pacific Agri-Lands Management in cooperation with E\&J Gallo Winery. The plantation structure of the vine rows has an east- 
west orientation with a row width of $3.35 \mathrm{~m}$ (11 feet). A cover crop grows in the interrows, occupying $\sim 2 \mathrm{~m}$, with bare soil strips along the vine rows spanning $\sim 0.7 \mathrm{~m}$. The vine height varies between $2 \mathrm{~m}$ and $2.5 \mathrm{~m}$ above ground level (agl), and vine biomass is concentrated mainly in the upper half of the vine canopy height. The actual vine canopy width varies spatially and temporally due to vine management practices. The study site has been a part of the Grape Remote sensing Atmospheric Profile and Evapotranspiration eXperiment (GRAPeX) program for several years. This program is conducted as a collaboration between the Agricultural Research Service in USDA, E\&J Gallo Winery, Utah State University, University of California in Davis, and others ${ }^{22,23}$.

A flight campaign was conducted by the AggieAir sUAS Program at Utah State University (https://uwrl.usu.edu/aggieair/). High-resolution, multispectral data were acquired for the entire field using sUAS during the growing season. Optical data, including red, blue, green, and near infrared bands, were acquired at $10-\mathrm{cm}$ spatial resolution. Thermal data were acquired using a microbolometer camera ${ }^{24}$ during the same flight and were radiometrically calibrated using the procedures discussed in Torres $2017^{25}$.

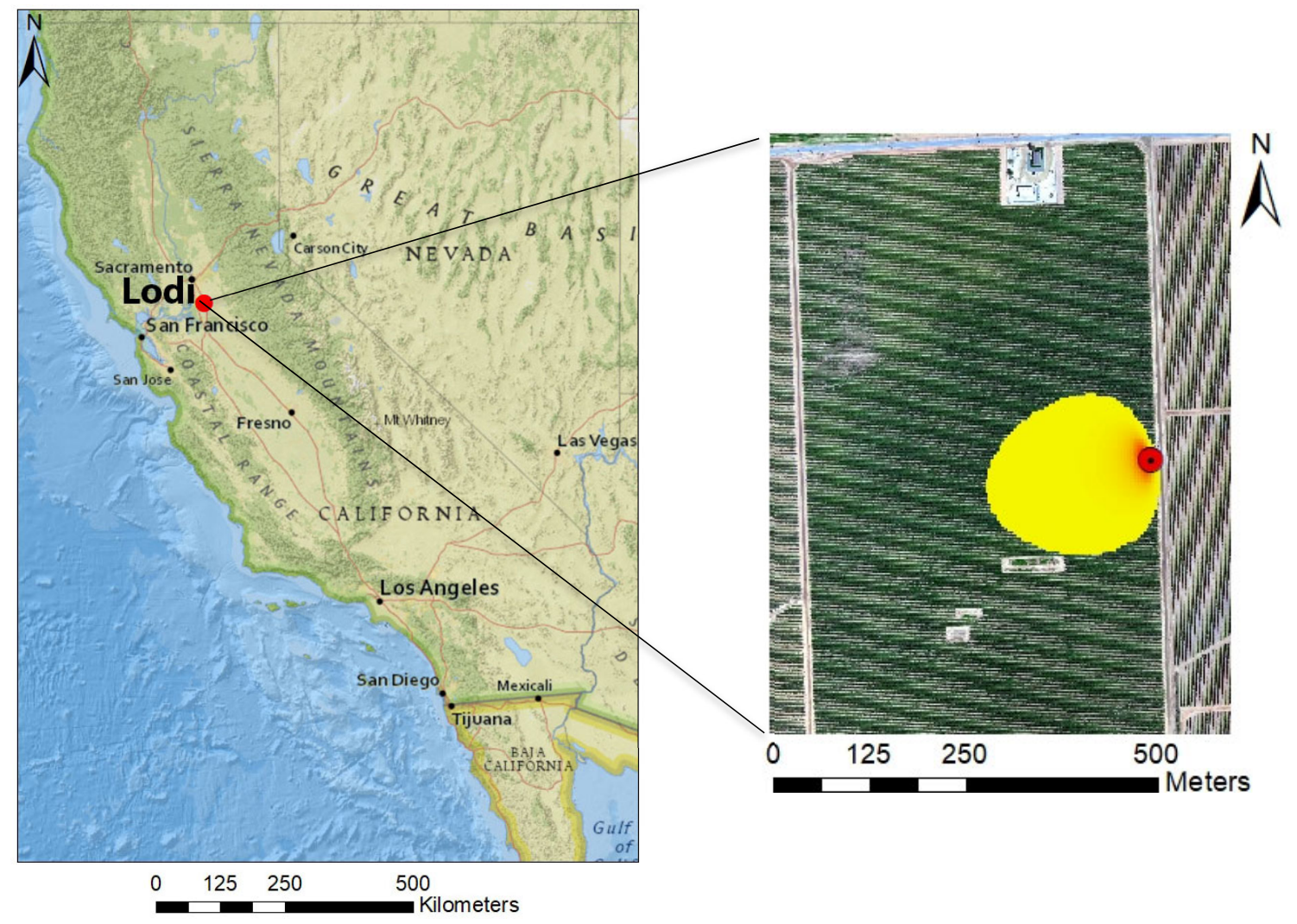

Figure 1. Layout of study area in Lodi, California, locations of north EC tower and example of $90 \%$ of EC footprint at Landsat time for August 09, 2014.

\subsection{Model Overview}

The TSEB model was originally developed by Norman et al $1995^{26}$ and has undergone several revisions to improve representation of the radiative and convective exchange between the canopy and soil system and the lower atmosphere ${ }^{10,26}$. The main concept behind the TSEB2T approach is to partition the radiative and turbulent fluxes between canopy and soil. In this case, sensible heat flux $(\mathrm{H})$ is partitioned between soil and canopy and relies mainly on $T_{c}$ and $T_{s}$ differences with the overlying atmosphere. As shown in Figure (2), the TSEB2T model separates $R_{n}, H$, and LE between vegetation and soil. The equations below are the mathematical expressions used to describe the TSEB2T model 


$$
\begin{gathered}
\mathrm{R}_{\mathrm{n}}=\mathrm{LE}+\mathrm{H}+\mathrm{G}, \\
\mathrm{R}_{\mathrm{nc}}=\mathrm{H}_{\mathrm{c}}+\mathrm{LE}_{\mathrm{c}}, \\
\mathrm{R}_{\mathrm{ns}}=\mathrm{H}_{\mathrm{s}}+\mathrm{LE}_{\mathrm{s}}+\mathrm{G},
\end{gathered}
$$

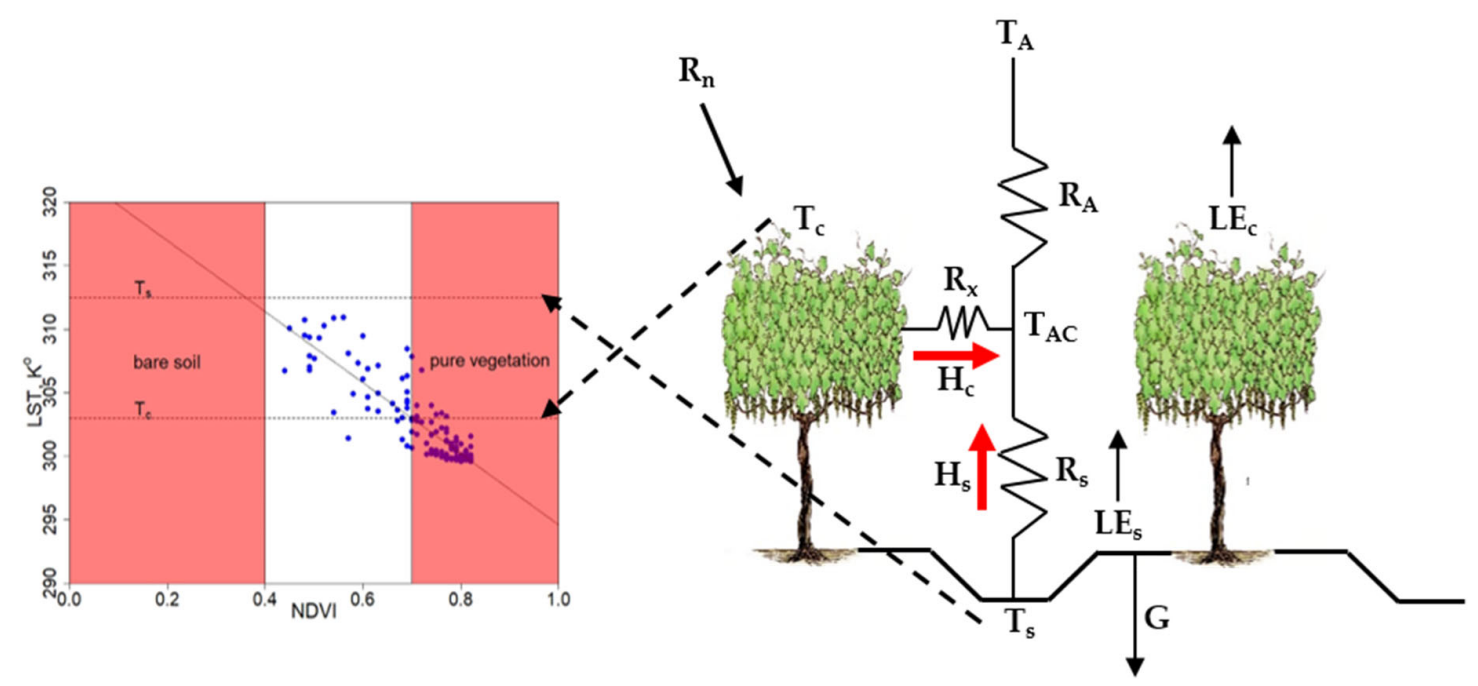

Figure 2. Schematic representation of TSEB2T model

where $R_{n}$ is the net radiation, $H$ is the sensible heat flux, $L E$ is the latent heat flux, and $G$ is the soil heat flux. All units of fluxes are in $\mathrm{W} / \mathrm{m}^{2} . \mathrm{T}_{\mathrm{s}}$ and $\mathrm{T}_{\mathrm{c}}$ are the soil and canopy temperature, respectively, derived from the LST and high enough resolution of optical data. Subscripts of c and s represent the canopy and soil components, respectively. $\mathrm{LE}_{\mathrm{c}}$ and $\mathrm{LE}_{\mathrm{s}}$ are solved as residuals when $\left(\mathrm{T}_{\mathrm{c}}\right.$ and $\left.\mathrm{T}_{\mathrm{s}}\right)$ observations are available.

Key inputs of TSEB are $T_{s}$ and $T_{c}, L A I, f_{c}, w_{c} / h_{c}$, and $h_{c}$ to parameterize the radiative and convective flux exchanges between soil/substrate and canopy. Other micro-meteorological data are also needed to run the model. The TSEB model was recommended by ${ }^{27}$ after comparing different remote sensing ET models. The results indicated that TSEB is a better model for ET estimation compared to others because it is less sensitive to roughness parameters. This low sensitivity to roughness parameters was recently verified for vineyards by Alfieri et al. $2019^{28}$. The TSEB model has been extensively tested for years over agroecosystems ${ }^{29,30,31}$, natural ecosystems ${ }^{32,33}$, and wetlands ${ }^{34,35}$.

The TSEB2T approach is a contextual TSEB that estimates $T_{\mathrm{S}}$ and $\mathrm{T}_{\mathrm{c}}$ from composite LST imagery using the relationship between vegetation index (VI) and LST, particularly LST-NDVI, to extract $T_{s}$ and $T_{c}$ within a spatial domain, which was $3.6 \mathrm{~m} \times 3.6 \mathrm{~m}$ for this study. $\mathrm{T}_{\mathrm{s}}$ and $\mathrm{T}_{\mathrm{c}}$ are calculated by averaging the temperature of pixels that are considered pure soil/substrate and pure canopy in a contextual spatial domain as shown in the two dimensional plot of the LST-NDVI relationship (see Figure. 2). The value of each pixel within the 3.6-m grid is assigned based on $\mathrm{T}_{\mathrm{c}}$ and $\mathrm{T}_{\mathrm{s}}$ and corresponds to the average temperature of areas considered pure vegetation and bare soil, respectively, at a 0.6-m spatial resolution. Threshold NDVI values of both soil/substrate and canopy $\left(\mathrm{NDVI}_{\mathrm{s}}\right.$ and $\mathrm{NDVI}_{\mathrm{c}}$, respectively) are used to classify the pixels of soil or canopy. $\mathrm{NDVI}_{\mathrm{s}}$ is determined by constructing a relationship between NDVI and the LAI curve when LAI in the interrows is nearly zero. On the other hand, $\mathrm{NDVI}_{\mathrm{c}}$ is detected using the mean value of pixels identified as pure vegetation in a binary (soil-vegetation) classification of a multispectral image. In cases of very dense vegetation where pure soil pixels do not exist or with sparse vegetation lacking pure vegetation pixels inside the spatial domain, a linear fit between LST and NDVI can be developed where $T_{s}$ and $T_{c}$ can be estimated as described in Figure (2). 


\subsection{Monte Carlo Simulation}

Sensitivity analysis (SA) techniques are usually carried out to identify whether a perturbation of parameters has a significant influence on the response of the model, that is, on the variable of interest. Wagener et al. $2001{ }^{36}$ pointed out that the low sensitivity of the model to any parameter can be simplified by replacing the parameters with constant values. The literature showed that sensitivity analysis is a standard step in any modelling study, but various updates continue to be carried out regularly to improve the SA techniques ${ }^{37,38}$. In this study, Monte Carlo (MC) analysis was used to generate a random selection of 1000 values of $\mathrm{NDVI}_{\mathrm{c}}$ and $\mathrm{NDVI}_{\mathrm{s}}$ thresholds. $\mathrm{MC}$ methods are defined as a subset of computational algorithms that rely on repeated random sampling to model outcomes in a process driven by uncertain factors. The uses of MC are incredibly varied and have led to number of groundbreaking discoveries in several fields.

The algorithm for this study has been designed to work as follows. First, threshold values of NDVI and $_{\mathrm{NDVI}}$ were randomly selected by creating a uniform distribution using Python programming. Uniform random selection, which assumes the values are equally distributed between a lower and upper boundary, has been used because the mean and the standard deviation to construct a Gaussian statistical distribution are unknown. Moreover, as indicated by Irmak et al. $2006^{39}$, no standard sensitivity analysis or common procedure has been proposed in previous studies for computing the sensitivity for any climate variable. For each iteration, a random selection for $\mathrm{NDVI}_{\mathrm{S}}$ and $\mathrm{NDVI}_{\mathrm{c}}$ is performed to calculate $T_{c}$ and $T_{s}$ as described in section (2.2). The selections are then used as inputs for the TSEB2T model. The main outputs of the TSEB2T model are the energy fluxes $\left(R_{n}, H, L E\right.$ and $\left.G\right)$ and other ancillary data. Each individual LE map obtained from the model is then multiplied by the weighted EC footprint/source area to obtain a single value for LE. After a few iterations of this procedure, multiple LE values are calculated and then compared against the true LE value measured by the EC tower.

\subsection{Statistical Evaluation of Uncertainty}

Statistics have been used to evaluate the impact of uncertainty associated with NDVI on LE estimation using MC simulation and TSEB2T. Meanwhile, these statistical measurements are helpful tools that can be used for quantifying the uncertainty /relative error associated with the model outputs, mainly LE. The main statistics involve the relative difference of $\mathrm{NDVI}_{\mathrm{s}}\left(\Delta \mathrm{NDVI}_{\mathrm{s}}\right)$, the relative difference of $\mathrm{NDVI}_{\mathrm{c}}\left(\Delta \mathrm{NDVI}_{\mathrm{c}}\right)$, the relative difference of LE $(\Delta \mathrm{LE})$, and the combined relative difference of $\mathrm{NDVI}_{\mathrm{s}}$ and $\mathrm{NDVI}_{\mathrm{c}}\left(\Delta \mathrm{NDVI}_{\mathrm{T}}\right)$. The mathematical expressions used for calculating each statistical measurement are shown as follows:

$$
\begin{gathered}
\Delta \mathrm{LE}=\frac{\mathrm{LE}_{\mathrm{s}}-\mathrm{LE}_{\mathrm{o}}}{\mathrm{LE}_{\mathrm{o}}} \times 100 \\
\Delta \mathrm{NDVI}_{\mathrm{s}}=\frac{\mathrm{NDVI}_{\mathrm{s}_{\mathrm{s}}}-\mathrm{NDVI}_{\mathrm{S}}}{\mathrm{NDVI}_{\mathrm{ST}}} \times 100 \\
\Delta \mathrm{NDVI}_{\mathrm{c}}=\frac{\mathrm{NDVI}_{\mathrm{c}_{\mathrm{S}}}-\mathrm{NDVI}_{\mathrm{c}}}{\mathrm{NDVI}_{\mathrm{c}}} \times 100 \\
\Delta \mathrm{NDVI}_{\mathrm{T}}=\sqrt{\Delta \mathrm{NDVI}_{\mathrm{s}}{ }^{2}+\Delta \mathrm{NDVI}_{\mathrm{c}}{ }^{2}}
\end{gathered}
$$

where $\mathrm{LE}_{\mathrm{S}}$ is the simulated latent heat flux, and $\mathrm{LE}_{\mathrm{o}}$ is the observed latent heat flux. All units of fluxes are $\mathrm{W} / \mathrm{m}^{2}$. $\mathrm{NDVI}_{\mathrm{S}_{\mathrm{S}}}$ and $\mathrm{NDVI}_{\mathrm{C}_{\mathrm{S}}}$ are the simulated $\mathrm{NDVI}_{\mathrm{s}}$ and $\mathrm{NDVI}_{\mathrm{c}}$, respectively. $\mathrm{NDVI}_{\mathrm{S}_{\mathrm{T}}}$ and $\mathrm{NDVI}_{\mathrm{S}_{\mathrm{T}}}$ are the true value of $\mathrm{NDVI}_{\mathrm{S}}$ and $\mathrm{NDVI}_{\mathrm{c}}$, respectively. $\triangle \mathrm{NDVI}_{\mathrm{T}}$ is the total relative difference combining $\Delta \mathrm{NDVI}_{\mathrm{s}}$ and $\Delta \mathrm{NDVI}_{\mathrm{c}}$. 


\section{RESULTS}

\subsection{NDVIs sensitivity analysis}

In the first scenario, the sensitivity analysis was performed only for $\mathrm{NDVI}_{\mathrm{s}}$ without a change in the $\mathrm{NDVI}_{\mathrm{c}}$ value. To do that, $1000 \mathrm{MC}$ simulations were used to model the probabilistic uncertainty of LE due to the uncertainty associated with $\mathrm{NDVI}_{\mathrm{s}}$ (see Figure (3)). The results indicate that LE most likely follows a uniform distribution similar to the $\mathrm{NDVI}_{\mathrm{s}}$ as shown in Figure (4), where the values range between $316 \mathrm{~W} / \mathrm{m}^{2}$ and $326 \mathrm{~W} / \mathrm{m}^{2}$. Although, the model considers all possible values of $\mathrm{NDVI}_{\mathrm{s}}$ under uncertainty conditions $(0.3-0.4)$, the model shows very low variability in LE values. This implies that the uncertainty in $\mathrm{NDVI}_{\mathrm{s}}$ is slightly influencing LE values when using the TSEB2T model.

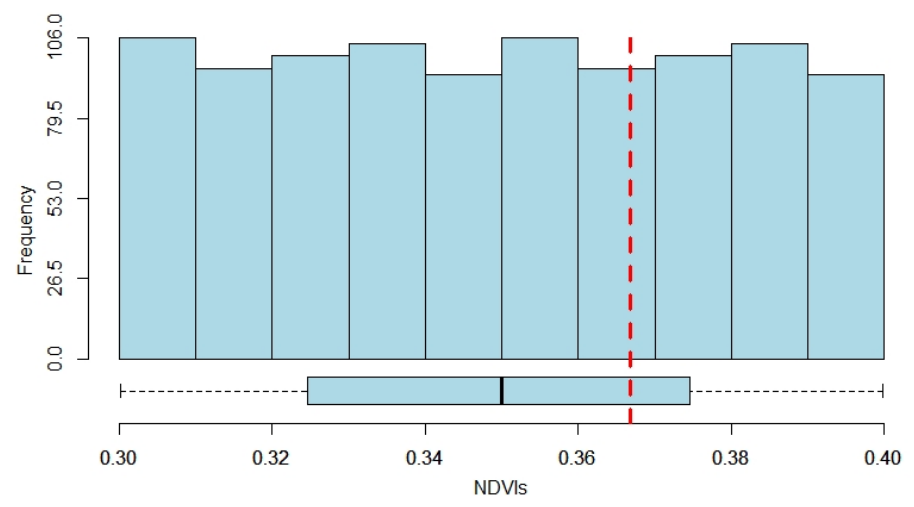

Figure 3. Histogram of $\mathrm{NDVI}_{\mathrm{s}}$ iterations using MC simulation. Vertical dash line is the NDVIs typical value used for soil temperature estimation.

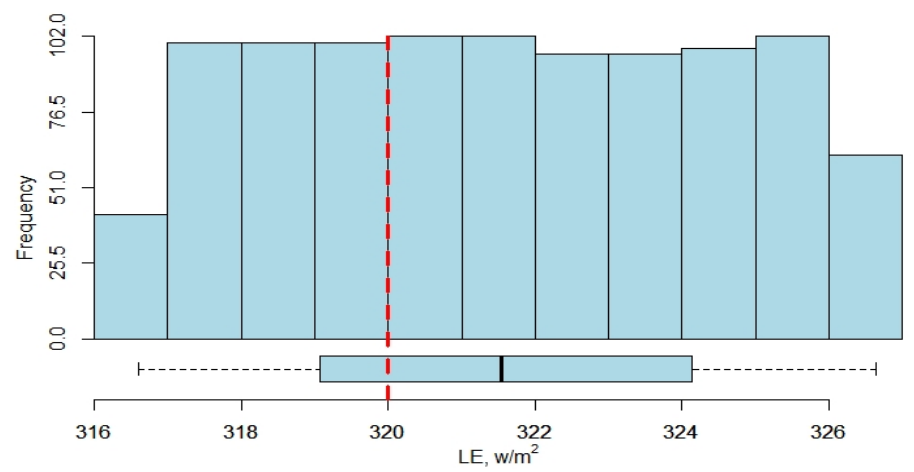

Figure 4. Histogram of LE values using MC simulation and TSEB2T model due to NDVIs uncertainty. Vertical dash line is the resulting LE value using the typical $\mathrm{NDVI}_{\mathrm{s}}$ value.

On the other hand, to quantify the error in $\mathrm{LE}$ with respect to uncertainty in $\mathrm{NDVI}_{\mathrm{s}}$, a relationship between $\Delta \mathrm{LE}$ and $\Delta \mathrm{NDVI}_{\mathrm{s}}$ was built as shown in Figure (5). The pattern between the two variables $\left(\Delta \mathrm{LE}\right.$ and $\left.\Delta \mathrm{NDVI}_{\mathrm{s}}\right)$ appears to be linear with determination coefficient $\left(\mathrm{R}^{2}\right)$ accounting for $\sim 1$. The results indicate that the $\mathrm{NDVI}_{\mathrm{S}}$ range of uncertainty is between $-18 \%$ and $9 \%$, while LE varies from $-1 \%$ to $2 \%$. The slope of the $\Delta \mathrm{LE}-\Delta \mathrm{NDVI} \mathrm{I}_{\mathrm{S}}$ regression line indicates that a $6 \%$ change in $\Delta \mathrm{NDVI}_{\mathrm{S}}$ is associated with a $-1 \%$ change in $\Delta \mathrm{LE}$. This means that the change in $\Delta \mathrm{LE}$ is relatively small compared with the rate of change in $\Delta \mathrm{NDVI}_{\mathrm{s}}$. 


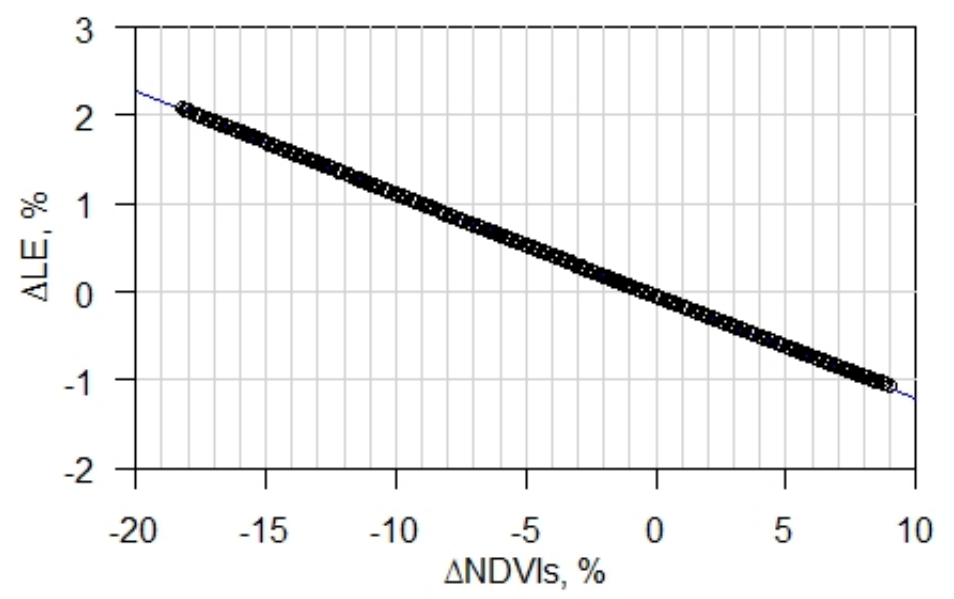

Figure 5. Relationship between $\Delta \mathrm{LE}$ and $\Delta \mathrm{NDVI}_{\mathrm{s}}$.

\subsection{NDVIc sensitivity analysis}

In the second scenario, the uncertainty analysis was considered only for $\mathrm{NDVI}_{\mathrm{c}}$ with no change in $\mathrm{NDVI}_{\mathrm{s}}$. The value of $\mathrm{NDVI}_{\mathrm{s}}$ was set at 0.37 according to the relationship between NDVI and LAI, while the simulated $\mathrm{NDVI}_{\mathrm{c}}$ values were selected randomly between (0.65 and 0.8) using $1000 \mathrm{MC}$ iterations (see Figure (6)). The results illustrated in Figure (7) show low variability in LE due to changes in NDVI $\mathrm{N}_{\mathrm{c}}$, with values ranging between $312 \mathrm{~W} / \mathrm{m}^{2}$ and $324 \mathrm{~W} / \mathrm{m}^{2}$. This implies that LE is slightly sensitive to the uncertainty associated with $\mathrm{NDVI}_{\mathrm{c}}$. Meanwhile, as shown in Figure (7), the results indicate that LE behaves like a uniform distribution similar to the $\mathrm{NDVI}_{\mathrm{c}}$ distribution.

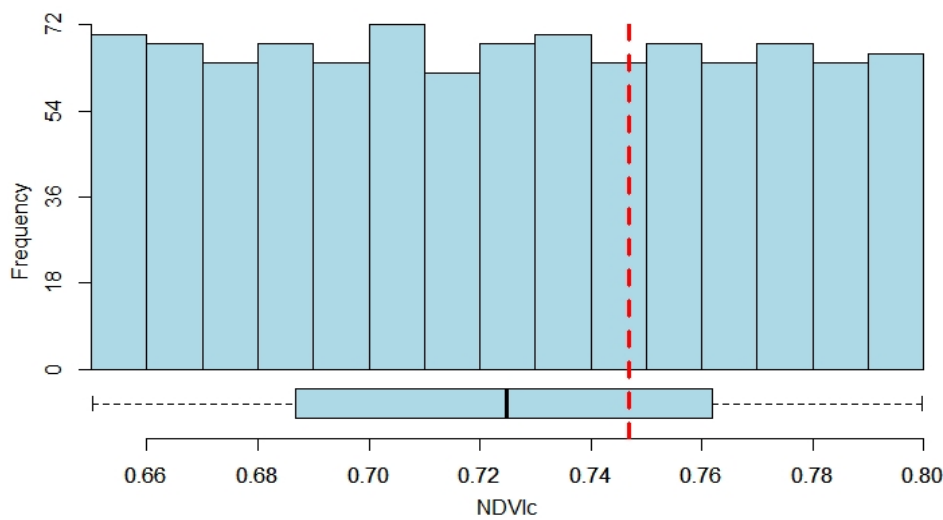

Figure 6. Histogram of $\mathrm{NDVI}_{\mathrm{c}}$ iterations using MC simulation. Vertical dash line is the $\mathrm{NDVI}_{\mathrm{c}}$ typical value used for soil temperature estimation. 


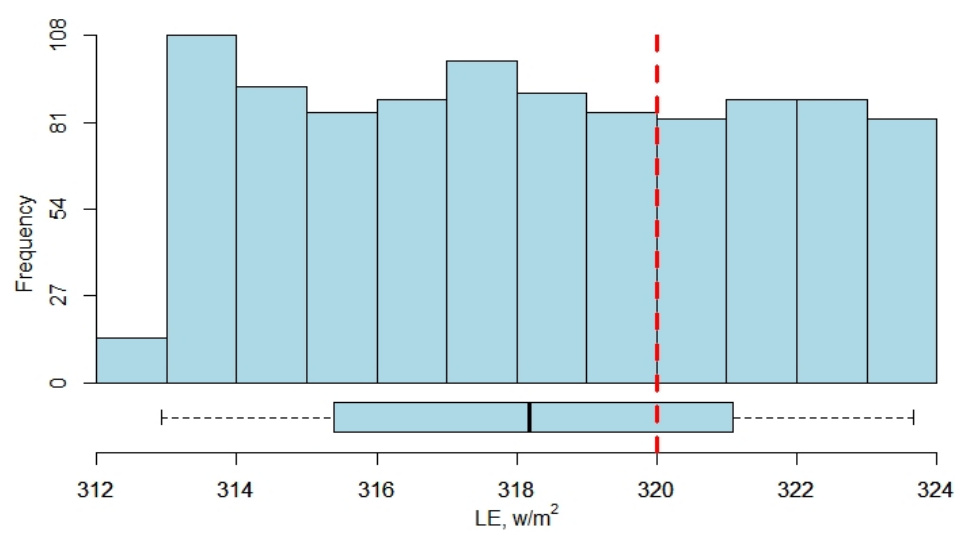

Figure 7. Histogram of LE values using MC simulation and TSEB2T model due to NDVI $I_{c}$ uncertainty. Vertical dash line is the resulting $L E$ value using the typical $\mathrm{NDVI}_{\mathrm{c}}$ value.

For a better understanding of the impact of uncertainty in $\mathrm{NDVI}_{\mathrm{c}}$ on the estimation of $\mathrm{LE}$, a relationship between $\triangle \mathrm{LE}$ and $\triangle \mathrm{NDVI}_{\mathrm{c}}$ was established as shown in Figure(8). The results demonstrate a strong linear relationship between $\Delta \mathrm{LE}$ and $\Delta \mathrm{NDVI}_{\mathrm{c}}$, with $\mathrm{R}^{2}$ of nearly 1 and a slope equal to 0.06 . This implies that a $6 \%$ change in $\Delta \mathrm{NDVI}_{\mathrm{c}}$ is associated with a $1 \%$ change in $\triangle \mathrm{LE}$ using the TSEB2T model. As shown in Figure (8), the uncertainty in $\mathrm{NDVI}_{\mathrm{c}}$ ranges from $-14 \%$ to $7 \%$, resulting in a relative error in the estimation of LE varying between $-2.2 \%$ and $1.2 \%$.

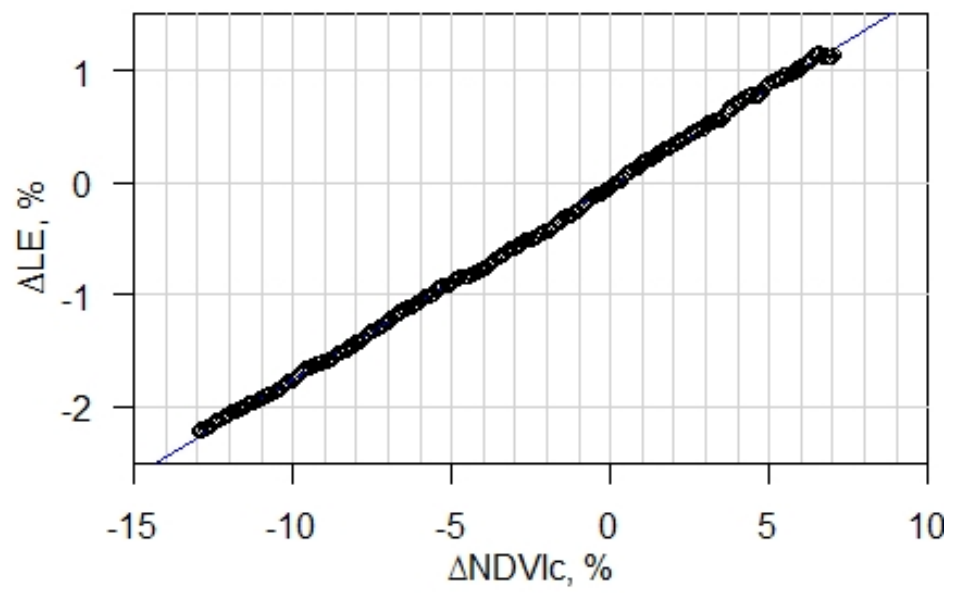

Figure 8. Relationship between $\Delta \mathrm{LE}$ and $\Delta \mathrm{NDVI}_{\mathrm{c}}$.

\subsection{Combined Uncertainty of NDVIs and NDVI}

In the last scenario, a sensitivity analysis was conducted to examine the simultaneous effect of $\mathrm{NDVI}_{\mathrm{s}}$ and $\mathrm{NDVI}_{\mathrm{c}}$ on LE estimate using $1000 \mathrm{MC}$ simulations. The simulated values of $\mathrm{NDVI}_{\mathrm{s}}$ were set between 0.3 and 0.4 , and the $\mathrm{NDVI}_{\mathrm{c}}$ values were chosen between 0.65 and 0.8 . The random selection for the simulation follows a continuous uniform distribution as shown in Figure (9) and Figure (10). As a result, the TSEB2T model indicates some degree of uncertainty in the LE estimate (see Figure (11)); however, the range of values is small, equaling $20 \mathrm{~W} / \mathrm{m}^{2}$. As displayed in Figure (11), the probabilistic uncertainty of LE is most likely a Gaussian distribution with mean and standard deviation accounting for $320 \mathrm{~W} / \mathrm{m}^{2}$ and $4.32 \mathrm{~W} / \mathrm{m}^{2}$, respectively. On the other hand, according to the boxplot illustrated at the bottom of Figure (11), 50\% of the LE values were found to be located between $317 \mathrm{~W} / \mathrm{m}^{2}$ and $323 \mathrm{~W} / \mathrm{m}^{2}$, with the true value at nearly $320 \mathrm{~W} / \mathrm{m}^{2}$. This implies that combining the uncertainty of $\mathrm{NDVI}_{\mathrm{s}}$ and $\mathrm{NDVI}_{\mathrm{c}}$ has little effect on LE estimation using the TSEB2T model. 


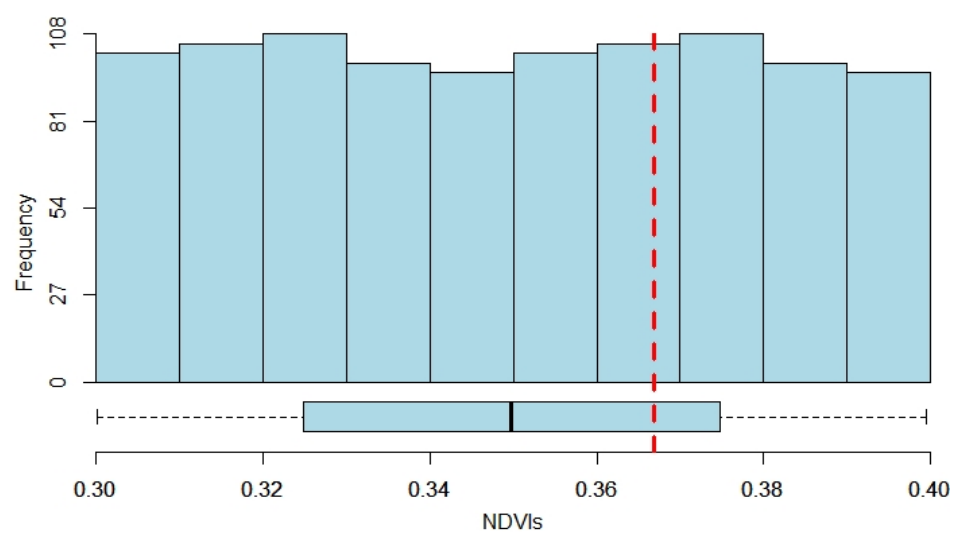

Figure 9. Histogram of $\mathrm{NDVI}_{\mathrm{s}}$ iterations using MC simulation. Vertical dash line is the NDVI $\mathrm{s}$ typical value used for soil temperature estimation.

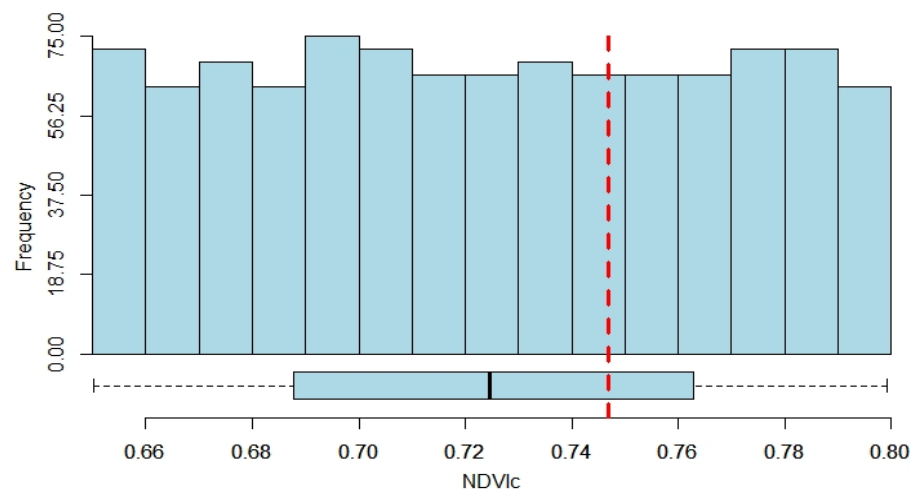

Figure 10. Histogram of NDVI $I_{c}$ iterations using MC simulation. Vertical dash line is the NDVI $I_{c}$ typical value used for soil temperature estimation.

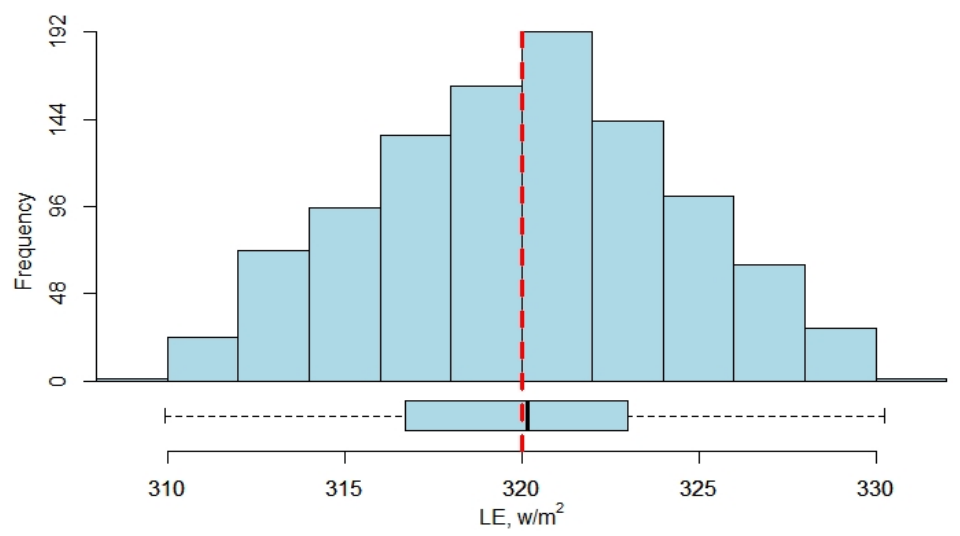

Figure 11. Histogram of LE values using MC simulation and TSEB2T model due to $\mathrm{NDVI}_{\mathrm{T}}$ uncertainty. Vertical dash line is the resulting $L E$ value using the typical $\mathrm{NDVI}_{\mathrm{s}}$ and $\mathrm{NDVI}_{\mathrm{c}}$ values.

Moreover, to measure the impact of the magnitude of $\mathrm{NDVI}_{\mathrm{c}}$ and $\mathrm{NDVI}_{\mathrm{s}}$ uncertainty components, the relationships of $\Delta \mathrm{LE}$ vs. $\Delta \mathrm{NDVI}_{\mathrm{s}}$ and $\Delta \mathrm{LE}$ vs. $\Delta \mathrm{NDVI}_{\mathrm{s}}$ were established separately. As shown in Figure (12), the results indicate that the uncertainty of $\mathrm{NDVI}_{\mathrm{s}}$ ranges between $-18 \%$ and $9 \%$, resulting in the relative error in $\mathrm{LE}$ varying from 
$-3 \%$ to $3 \%$. Although the uncertainty range of $\mathrm{NDVI}_{\mathrm{s}}$ is larger than $\mathrm{NDVI}_{\mathrm{c}}$, the relative error domain associated with LE gives the same results. This implies that LE is more sensitive to changes in $\mathrm{NDVI}_{\mathrm{c}}$ than $\mathrm{NDVI}_{\mathrm{s}}$.
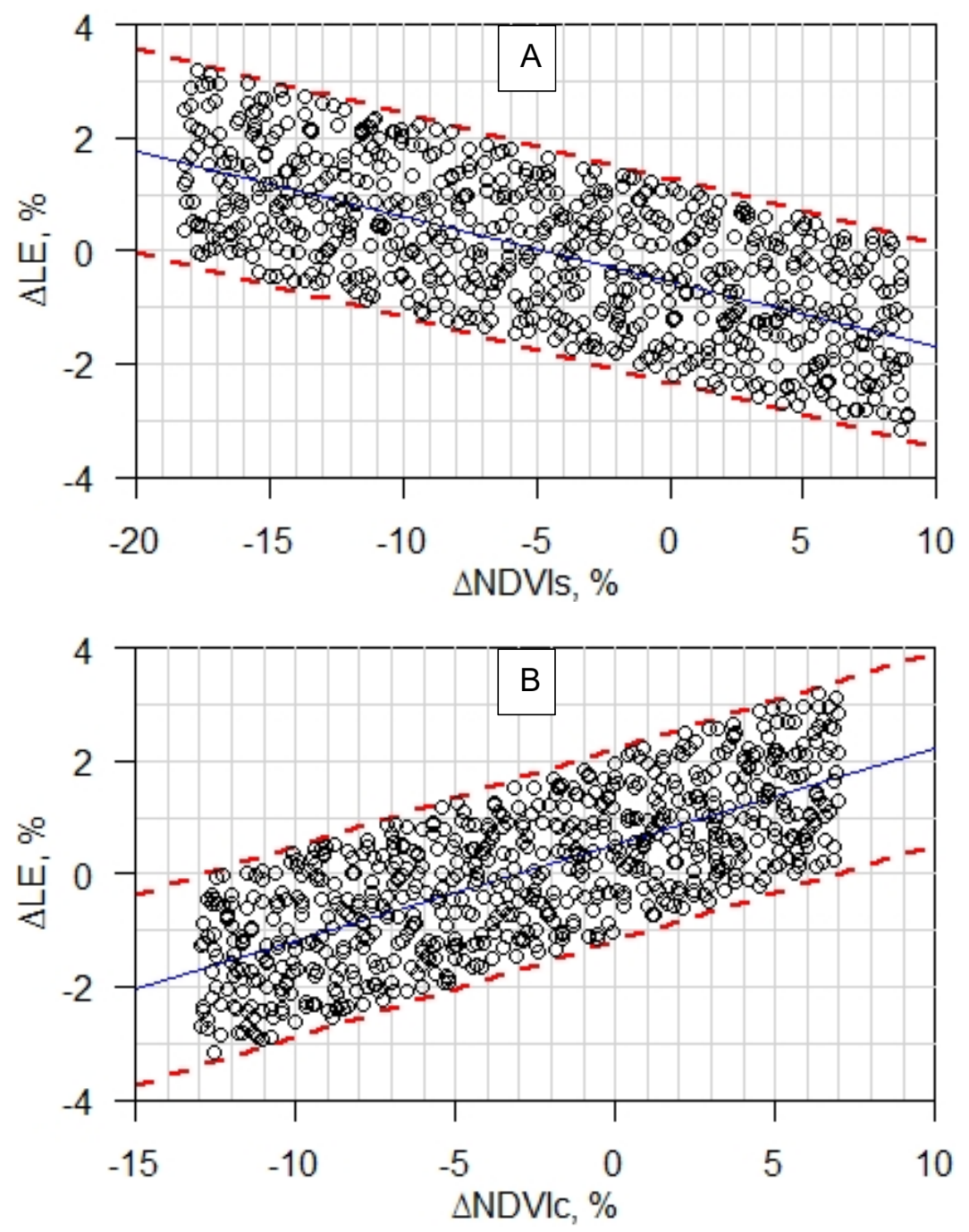

Figure 12. Relationship between $\Delta \mathrm{LE}$ (top) and $\triangle \mathrm{NDVI}_{\mathrm{s}}$ and $\Delta \mathrm{LE}$ and $\Delta \mathrm{NDVI}_{\mathrm{c}}$ (bottom).

As demonstrated in Figure (13), the combined/total uncertainty associated with NDVI (hereafter called $\left.\mathrm{NDVI}_{\mathrm{T}}\right)$ is calculated and evaluated against the absolute $\Delta \mathrm{LE}(|\Delta \mathrm{LE}|)$. A high variation in $|\Delta \mathrm{LE}|$ occurs as the value of $\mathrm{NDVI}_{\mathrm{T}}$ increases. Although, the range of $\mathrm{NDVI}_{\mathrm{T}}$ is wide, varying from $0 \%$ to $20 \%$, the domain of relative error in $\mathrm{LE}$ values is small, ranging between $0 \%$ and $4 \%$. Meanwhile, the results indicate that a $1 \%$ change in $\Delta \mathrm{NDVI}_{\mathrm{T}}$ yields a change in $|\Delta \mathrm{LE}|$ of less than $0.25 \%$. 


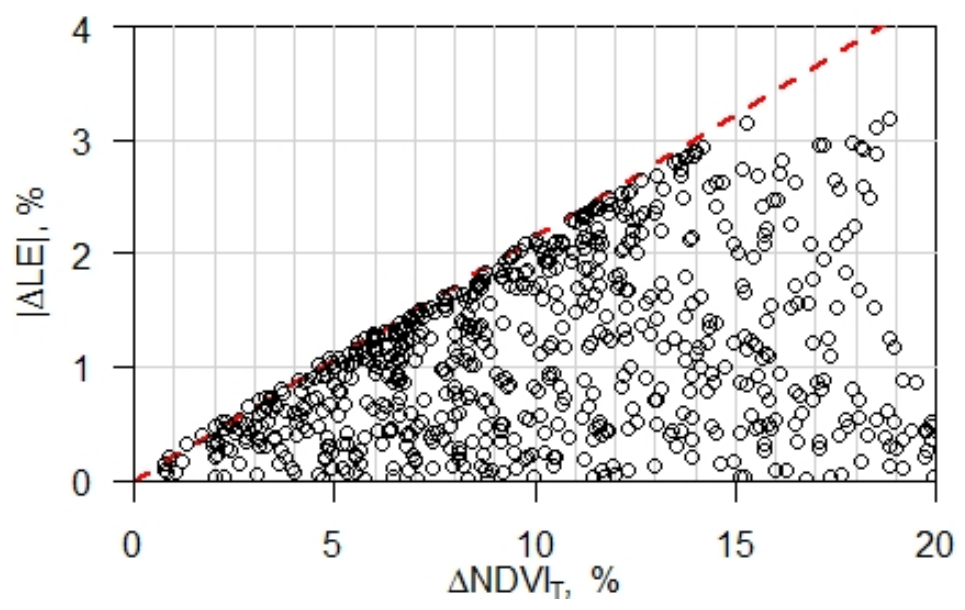

Figure 13. Relationship between $|\Delta \mathrm{LE}|$ and $\Delta \mathrm{NDVI}_{\mathrm{T}}$.

\section{CONCLUSION}

The objective of this study was to evaluate the effect of uncertainty in $T_{s}$ and $T_{c}$ estimation on surface energy fluxes, mainly LE, by applying a Monte Carlo simulation on NDVI thresholds used to define canopy and soil temperatures. In this study, three scenarios have been considered for analysis, with $1000 \mathrm{MC}$ simulations performed for each scenario to generate the probabilistic distribution of NDVI thresholds. The first scenario was a sensitivity analysis performed only for $\mathrm{NDVI}_{\mathrm{s}}$ with no change in the $\mathrm{NDVI}_{\mathrm{c}}$ value. In the second scenario, the uncertainty analysis was considered only for $\mathrm{NDVI}_{\mathrm{c}}$ with no change in $\mathrm{NDVI}_{\mathrm{s}}$. In the last scenario, the sensitivity analysis was conducted to examine the combined effect of $\mathrm{NDVI}_{\mathrm{S}}$ and $\mathrm{NDVI}_{\mathrm{c}}$ simultaneously. In the first two scenarios, the results indicate the uncertainty associated with $\mathrm{NDVI}_{\mathrm{s}}$ or $\mathrm{NDVI}_{\mathrm{c}}$ is influencing LE values only slightly using the TSEB2T model. The observed relative error of LE corresponding to $\mathrm{NDVI}_{\mathrm{s}}$ uncertainty was between $-1 \%$ and $2 \%$, while for $\mathrm{NDVI}_{\mathrm{c}}$ uncertainty, the relative error was between $-2.2 \%$ and $1.2 \%$. Meanwhile, the results indicate that a $6 \%$ change rate in $\Delta \mathrm{NDVI}_{\mathrm{s}}$ is associated with a $-1 \%$ change in $\triangle \mathrm{LE}$. However, due to $\mathrm{NDVI}_{\mathrm{c}}$ uncertainty, a $6 \%$ change in $\Delta \mathrm{NDVI}_{\mathrm{c}}$ causes a $1 \%$ change in $\triangle \mathrm{LE}$ using TSEB2T model. Based on the results obtained from the third scenario, a high variation in $|\Delta \mathrm{LE}|$ occurs as the value of $\mathrm{NDVI}_{\mathrm{T}}$ increases. Although, the range of $\mathrm{NDVI}_{\mathrm{T}}$ is wide, varying from $0 \%$ to $20 \%$, the domain of relative error for the absolute values of LE is small, ranging between $0 \%$ and $4 \%$. Meanwhile, the results show that a $1 \%$ change in $\triangle \mathrm{NDVI}_{\mathrm{T}}$ yields a change in $|\Delta \mathrm{LE}|$ of less than $0.25 \%$.

The results of this analysis indicate that an exact number for NDVI thresholds is not necessary for the TSEB2T model, as long these values are estimated with a certain accuracy. This finding does not represent different ET models where NDVI thresholds are used (e.g. METRIC, SEBAL, NDVI-K ${ }_{c}$ ), therefore a similar analysis would be necessary for these. 
Funding: Funding provided by E.\&J. Gallo Winery. Utah Water Research Laboratory contributed towards the acquisition and processing of the ground truth and UAV imagery data collected during GRAPEX IOPs. We would like to acknowledge the financial support for this research from NASA Applied Sciences-Water Resources Program and the USDA Non Assistance Cooperative Agreement 58-8042-5-092 funding. USDA is an equal opportunity provider and employer.

Acknowledgments: We would like to thank Aggieair Service Center team (Ian Gowing, Mark Winkelaar, and Shannon Syrstad) for their extraordinary support in this research, whose cooperation greatly improved the data collection and data processing, and the staff of the Viticulture, Chemistry and Enology Division of E.\&J. Gallo Winery for their assistance in the collection and processing of field data during GRAPEX IOPs. This project would not have been possible without the cooperation of Mr. Ernie Dosio of Pacific Agri Lands Management, along with the Sierra Loma vineyard staff, for logistical support of GRAPEX field and research activities. The authors would like to thank Carri Richards for editing this paper.

Conflicts of Interest: The authors declare no conflict of interest. 


\section{REFERENCES}

[1] Talsma, Carl, Stephen Good, Diego Miralles, Joshua Fisher, Brecht Martens, Carlos Jimenez, and Adam Purdy. 2018. "Sensitivity of Evapotranspiration Components in Remote Sensing-Based Models." Remote Sensing. https://doi.org/10.3390/rs10101601.

[2] Sun, Zhigang, Qinxue Wang, Ochirbat Batkhishig, and Zhu Ouyang. 2016. "Relationship between Evapotranspiration and Land Surface Temperature under Energy- and Water-Limited Conditions in Dry and Cold Climates." Advances in Meteorology. https://doi.org/10.1155/2016/1835487.

[3] Anderson, Martha C., Christopher Hain, Brian Wardlow, Agustin Pimstein, John R. Mecikalski, and William P. Kustas. 2011. "Evaluation of Drought Indices Based on Thermal Remote Sensing of Evapotranspiration over the Continental United States.” Journal of Climate. https://doi.org/10.1175/2010jcli3812.1.

[4] Alberto, Ma Carmelita R., James R. Quilty, Roland J. Buresh, Reiner Wassmann, Sam Haidar, Teodoro Q. Correa, and Joseph M. Sandro. 2014. "Actual Evapotranspiration and Dual Crop Coefficients for Dry-Seeded Rice and Hybrid Maize Grown with Overhead Sprinkler Irrigation.” Agricultural Water Management. https://doi.org/10.1016/j.agwat.2014.01.005.

[5] "National Water Summary 1987: Hydrologic Events and Water Supply and Use." 1990. https://doi.org/10.3133/wsp2350.

[6] Kustas, William P., Joseph G. Alfieri, Martha C. Anderson, Paul D. Colaizzi, John H. Prueger, Steven R. Evett, Christopher M. U. Neale, et al. 2012. "Evaluating the Two-Source Energy Balance Model Using Local Thermal and Surface Flux Observations in a Strongly Advective Irrigated Agricultural Area." Advances in Water Resources. https://doi.org/10.1016/j.advwatres.2012.07.005.

[7] Swinbank, W. C. 1951. "THE MEASUREMENT OF VERTICAL TRANSFER OF HEAT AND WATER VAPOR BY EDDIES IN THE LOWER ATMOSPHERE.” Journal of Meteorology. https://doi.org/2.0.co;2">10.1175/1520-0469(1951)008<0135:tmovto>2.0.co;2.

[8] Angus, W. O. Pruitt And D. E., and W. O. Pruitt and D. E. Angus. 1960. "Large Weighing Lysimeter for Measuring Evapotranspiration." Transactions of the ASAE. https://doi.org/10.13031/2013.41105.

[9] Meijninger, W. M. L., A. E. Green, O. K. Hartogensis, W. Kohsiek, J. C. B. Hoedjes, R. M. Zuurbier, and H. A. R. De Bruin. 2002. "Determination of Area-Averaged Water Vapour Fluxes with Large Aperture and Radio Wave Scintillometers over a Heterogeneous Surface - Flevoland Field Experiment.” Boundary-Layer Meteorology. https://doi.org/10.1023/a:1019683616097.

[10] Nassar, Ayman; Alfonso Torres-Rua, William Kustas, Hector Nieto, Mac McKee, Lawrence Hipps, David Stevens, et al. 2020. "Influence of Model Grid Size on the Estimation of Surface Fluxes Using the Two Source Energy Balance Model and sUAS Imagery in Vineyards.” Remote Sensing. https://doi.org/10.3390/rs12030342.

[11]Elhag, Mohamed, Aris Psilovikos, Ioannis Manakos, and Kostas Perakis. 2011. "Application of the Sebs Water Balance Model in Estimating Daily Evapotranspiration and Evaporative Fraction from Remote Sensing Data Over the Nile Delta." Water Resources Management. https://doi.org/10.1007/s11269-011-9835-9.

[12] McShane, Ryan R., Katelyn P. Driscoll, and Roy Sando. 2017. “A Review of Surface Energy Balance Models for Estimating Actual Evapotranspiration with Remote Sensing at High Spatiotemporal Resolution over Large Extents.” Scientific Investigations Report. https://doi.org/10.3133/sir20175087.

[13] McKee, Mac, Alfonso F. Torres-Rua, Mahyar Aboutalebi, Ayman Nassar, Calvin Coopmans, William P. Kustas, Feng Gao, Nicholas Dokoozlian, Luis Sanchez, and Maria M. Alsina. 2019. "Challenges That beyond-Visual-Lineof-Sight Technology Will Create for UAS-Based Remote Sensing in Agriculture (Conference Presentation)." Autonomous Air and Ground Sensing Systems for Agricultural Optimization and Phenotyping IV. https://doi.org/10.1117/12.2520248.

[14] Prata, A. J., V. Caselles, C. Coll, J. A. Sobrino, and C. Ottlé. 1995. "Thermal Remote Sensing of Land Surface Temperature from Satellites: Current Status and Future Prospects." Remote Sensing Reviews. https://doi.org/10.1080/02757259509532285.

[15]Neteler, Markus. 2010. "Estimating Daily Land Surface Temperatures in Mountainous Environments by Reconstructed MODIS LST Data.” Remote Sensing. https://doi.org/10.3390/rs1020333. 
[16] Kustas, W. P., and J. M. Norman. 1996. "Use of Remote Sensing for Evapotranspiration Monitoring over Land Surfaces.” Hydrological Sciences Journal. https://doi.org/10.1080/02626669609491522.

[17] Li, Zhao-Liang, Bo-Hui Tang, Hua Wu, Huazhong Ren, Guangjian Yan, Zhengming Wan, Isabel F. Trigo, and José A. Sobrino. 2013. "Satellite-Derived Land Surface Temperature: Current Status and Perspectives." Remote Sensing of Environment. https://doi.org/10.1016/j.rse.2012.12.008.

[18] Nassar, Ayman; Nieto, Hector; Aboutalebi, Mahyar; TorresRue, Alfonso; McKee, Mac; Kustas, William; Prueger, John; McKee, Lynn; Alfieri, Joseph; Hipps, Lawrence; et al. Pixel Resolution Sensitivity Analysis for the Estimation of Evapotranspiration Using the Two Source Energy Balance Model and sUAS Imagery under Agricultural Complex Canopy Environments; American Geophysical Union (AGU): Washington, DC, USA, 2018

[19] Nassar, Ayman; Torres-Rua, Alfonso; Alfieri, Joseph; Hipps, Lawrence; Prueger, John; Nieto, Hector; Alsina, Maria; McKee, Lynn; White, William; Kustas, William; McKee, Mac; Coopmans, Calvin; Sanchez, Luis; Dokoozlian, N. Assessment of High-Resolution Daily Evapotranspiration Models Using Instantaneous sUAS ET in Grapevine Vineyards; American Geophysical Union (AGU): California, USA, 2019

[20] Nassar, Ayman; Torres-Rua, Alfonso; McKee, Mac; Kustas, William; Coopmans, Calvin; Nieto, Hector; Hipps, Lawerence. Assessment of UAV Flight Times for Estimation of Daily High Resolution Evapotranspiration in Complex Agricultural Canopy Environments. UCOWR/NIWR Annual Water Resources Conference: Utah, USA, 2019

[21] McKee, Mac, Ayman Nassar, Alfonso Torres-Rua, Mahyar Aboutalebi, and William Kustas. 2018. "Implications of Sensor Inconsistencies and Remote Sensing Error in the Use of Small Unmanned Aerial Systems for Generation of Information Products for Agricultural Management." Proceedings of SPIE The International Society for Optical Engineering 10664 (July). https://doi.org/10.1117/12.2305826.

[22] Nassar, Ayman, Alfonso F. Torres-Rua, Joseph G. Alfieri, Lawrence E. Hipps, John H. Prueger, Hector Nieto, Maria Mar Alsina, et al. 2020. "To What Extend Does the Eddy Covariance Footprint Cutoff Influence the Estimation of Surface Energy Fluxes Using Two Source Energy Balance Model and High-Resolution Imagery in Commercial Vineyards? (Conference Presentation)." Autonomous Air and Ground Sensing Systems for Agricultural Optimization and Phenotyping V. https://doi.org/10.1117/12.2558777.

[23] Nassar, Ayman, Alfonso F. Torres-Rua, Hector Nieto, Joseph G. Alfieri, Lawrence E. Hipps, John H. Prueger, Maria M. Alsina, et al. 2020. "Implications of Soil and Canopy Temperature Uncertainty in the Estimation of Surface Energy Fluxes Using TSEB2T and High-Resolution Imagery in Commercial Vineyards (Conference Presentation)." Autonomous Air and Ground Sensing Systems for Agricultural Optimization and Phenotyping V. https://doi.org/10.1117/12.2558715.

[24] Torres-Rua, Alfonso F., Mahyar Aboutalebi, Timothy Wright, Ayman Nassar, Pierre Guillevic, Lawrence Hipps, Feng Gao, et al. 2019. "Estimation of Surface Thermal Emissivity in a Vineyard for UAV Microbolometer Thermal Cameras Using NASA HyTES Hyperspectral Thermal, and Landsat and AggieAir Optical Data.” Autonomous Air and Ground Sensing Systems for Agricultural Optimization and Phenotyping IV. https://doi.org/10.1117/12.2518958.

[25] Torres-Rua, Alfonso. 2017. "Vicarious Calibration of sUAS Microbolometer Temperature Imagery for Estimation of Radiometric Land Surface Temperature.” Sensors 17 (7). https://doi.org/10.3390/s17071499.

[26] Norman, J. M., W. P. Kustas, and K. S. Humes. 1995. "Source Approach for Estimating Soil and Vegetation Energy Fluxes in Observations of Directional Radiometric Surface Temperature.” Agricultural and Forest Meteorology. https://doi.org/10.1016/0168-1923(95)02265-y.

[27] Chirouze, J., G. Boulet, L. Jarlan, R. Fieuzal, J. C. Rodriguez, J. Ezzahar, S. Er-Raki, et al. 2014. "Intercomparison of Four Remote-Sensing-Based Energy Balance Methods to Retrieve Surface Evapotranspiration and Water Stress of Irrigated Fields in Semi-Arid Climate.” Hydrology and Earth System Sciences 18 (3): 1165-88.

[28] Alfieri, Joseph G., William P. Kustas, Hector Nieto, John H. Prueger, Lawrence E. Hipps, Lynn G. McKee, Feng Gao, and Sebastian Los. 2019. "Influence of Wind Direction on the Surface Roughness of Vineyards." Irrigation Science. https://doi.org/10.1007/s00271-018-0610-z. 
[29] Kustas, W. P., J. G. Alfieri, H. Nieto, T. G. Wilson, F. Gao, and M. C. Anderson. 2019. "Utility of the Two-Source Energy Balance (TSEB) Model in Vine and Interrow Flux Partitioning over the Growing Season." Irrigation Science. https://doi.org/10.1007/s00271-018-0586-8.

[30] Bigeard, Guillaume, Benoit Coudert, Jonas Chirouze, Salah Er-Raki, Gilles Boulet, Eric Ceschia, and Lionel Jarlan. n.d. "Evapotranspiration Monitoring Based on Thermal Infrared Data over Agricultural Landscapes: Comparison of a Simple Energy Budget Model and a SVAT Model.” https://doi.org/10.5194/hess-2018-295.

[31] Kustas, William, and Martha Anderson. 2009. “Advances in Thermal Infrared Remote Sensing for Land Surface Modeling." Agricultural and Forest Meteorology. https://doi.org/10.1016/j.agrformet.2009.05.016.

[32] Yang, Yongmin, Jianxiu Qiu, Renhua Zhang, Shifeng Huang, Sheng Chen, Hui Wang, Jiashun Luo, and Yue Fan. 2018. "Intercomparison of Three Two-Source Energy Balance Models for Partitioning Evaporation and Transpiration in Semiarid Climates.” Remote Sensing. https://doi.org/10.3390/rs10071149.

[33] Andreu, Ana, William Kustas, Maria Polo, Arnaud Carrara, and Maria González-Dugo. 2018. "Modeling Surface Energy Fluxes over a Dehesa (Oak Savanna) Ecosystem Using a Thermal Based Two-Source Energy Balance Model (TSEB) I.” Remote Sensing. https://doi.org/10.3390/rs10040567.

[34] Yao, Wei, Min Han, and Shiguo Xu. 2010. "Estimating the Regional Evapotranspiration in Zhalong Wetland with the Two-Source Energy Balance (TSEB) Model and Landsat7/ETM Images." Ecological Informatics. https://doi.org/10.1016/j.ecoinf.2010.06.002.

[35] Anderson, Martha, Feng Gao, Kyle Knipper, Christopher Hain, Wayne Dulaney, Dennis Baldocchi, Elke Eichelmann, et al. 2018. "Field-Scale Assessment of Land and Water Use Change over the California Delta Using Remote Sensing.” Remote Sensing. https://doi.org/10.3390/rs10060889.

[36] Wagener, T., D. P. Boyle, M. J. Lees, H. S. Wheater, H. V. Gupta, and S. Sorooshian. 2001. “A Framework for Development and Application of Hydrological Models." Hydrology and Earth System Sciences. https://doi.org/10.5194/hess-5-13-2001.

[37] Razavi, Saman, and Hoshin V. Gupta. 2016. “A New Framework for Comprehensive, Robust, and Efficient Global Sensitivity Analysis: 1. Theory.” Water Resources Research. https://doi.org/10.1002/2015wr017558.

[38] Pianosi, Francesca, and Thorsten Wagener. 2015. "A Simple and Efficient Method for Global Sensitivity Analysis Based on Cumulative Distribution Functions." Environmental Modelling \& Software. https://doi.org/10.1016/j.envsoft.2015.01.004.

[39] Irmak, Suat, José O. Payero, Derrel L. Martin, Ayse Irmak, and Terry A. Howell. 2006. "Sensitivity Analyses and Sensitivity Coefficients of Standardized Daily ASCE-Penman-Monteith Equation." Journal of Irrigation and Drainage Engineering. https://doi.org/10.1061/(asce)0733-9437(2006)132:6(564). 